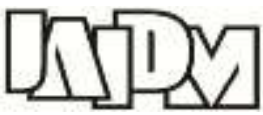

Journal of AI and Data Mining

Vol 4, No 2, 2016, 243-251

10.5829/idosi.JAIDM.2016.04.02.13

\title{
An indirect adaptive neuro-fuzzy speed control of induction motors
}

\author{
M. Vahedi*, M. Hadad Zarif and A. Akbarzadeh Kalat \\ Faculty of Electrical \& Robotic Engineering, Shahrood University of Technology, Shahrood, Iran. \\ Received 18 December 2014; Accepted 24 June 2015 \\ *Corresponding author: vahedi.mojtaba@gmail.com (M.Vahedi).
}

\begin{abstract}
This paper presents an indirect adaptive system based on neuro-fuzzy approximators for the speed control of induction motors. The uncertainty including parametric variations, the external load disturbance and unmodeled dynamics is estimated and compensated by designing neuro-fuzzy systems. The contribution of this paper is presenting a stability analysis for neuro-fuzzy speed control of induction motors. The online training of the neuro-fuzzy systems is based on the Lyapunov stability analysis and the reconstruction errors of the neuro-fuzzy systems are compensated in order to guarantee the asymptotic convergence of the speed tracking error. Moreover, to improve the control system performance and reduce the chattering, a PI structure is used to produce the input of the neuro-fuzzy systems. Finally, simulation results verify high performance characteristics and robustness of the proposed control system against plant parameter variation, external load and input voltage disturbance.
\end{abstract}

Keywords: Induction Motor; Indirect Adaptive Estimation; Stability Analysis; Reconstruction Error.

Control; Neuro-fuzzy Approximators; Uncertainty

\section{Introduction}

In the last few decades, the speed control of induction motors (IMs) has been the focus of widespread researches [1-6]. However, the closed loop control system stability has not been guaranteed in most of these researches. Moreover, the asymptotic convergence of the speed tracking error is very important in most industrial applications and should be mathematically guaranteed. To solve this problem, many Lyapunov based control algorithms for IMs have been presented in the literature [7-9]. However, these researches have focused on the position control of induction servo motors and the boundedness of fluxes and currents has not been guaranteed. Recently, a speed control system with stability analysis has been presented based on the sliding mode control [10]. In that research, boundedness of fluxes and currents is guaranteed using some limiters. However, the proposed control law contains the sign function which may cause the undesirable chattering phenomenon. Thus, presenting a continuous control law with stability analysis is required. Model based control approaches, such as feedback linearization, are very popular and attractive. However, they are not suitable for IMs due the variations of the external load disturbance. To enhance the performance of feedback linearization and overcome uncertainties including parametric uncertainty, un-modeled dynamics and external disturbances, considerable researches have been carried out in the field of adaptive and robust control [11-16]. Adaptive control can overcome parametric uncertainty [17], while robust control can compensate both parametric and nonparametric uncertainty. In order to design an adaptive control law, the structure of the system dynamics should be available. In other words, the regressor vector should be known. Thus, conventional adaptive control laws may not be successful for complicated systems with unknown dynamics. Although robust control can overcome nonparametric uncertainties, but the upper bound of uncertainties should be known [18]. Overestimation of this bound will increase the amplitude of the control signal and consequently may damage the system. On the other hand, underestimation of this bound will deteriorate the 
system performance by increasing the tracking error [19,20]. Moreover, in some robust control approaches, such as sliding mode control, the control law is discontinuous which may result in the chattering phenomenon [21].

In order to improve the performance of adaptive or robust controllers, many researchers have applied artificial intelligence. Various neural networks and fuzzy systems are widely used in adaptive and robust control [22-26] due to their universal approximation property. These researches can be considered as different efforts made toward common objectives which are estimation and compensation of uncertainty. Generally, adaptive neuro-fuzzy approaches can be classified into two main groups: direct and indirect. In direct approaches, an adaptive neurofuzzy system is designed to approximate the ideal control law, while in indirect methods, first the unknown nonlinear dynamics of the systems are identified and then a control input is generated based on the universal approximation theorem [27]. According to this theorem, neuro fuzzy systems can approximate any nonlinear functions with arbitrary small approximation error. An adaptive fuzzy speed control of IMs is presented in [22] in which the gains of the sliding mode controller are adjusted by a fuzzy system and the centers of fuzzy sets are updated by an adaptation law: the gain adjustment to compensate the uncertainty and the centers updating to reduce the control effort chattering. A multivariable adaptive fuzzy speed controller for IMs is proposed in [23] where the approximation of the nonlinear parameters in the feedback linearization control law is based on fuzzy logic. The advantage of this paper in comparison with previous related works is that it does not need any prior knowledge of plant dynamics. In [24], an adaptive speed control using a neural network representing the feedback linearization law has been presented. Also an error compensator is added in order to compensate the approximation error between the neural network and the feedback linearization law. In [25] adaptive neuro-fuzzy systems for speed control of IM have been represented. In the designed neurofuzzy scheme, neural network techniques have been used to choose a proper rule base, which has been achieved by using the back propagation algorithm. This integrated approach improves the system performance, efficiency, reliability, cost effectiveness and dynamism of the designed controller. Zerikat and Hekroun [26] have improved an adaptive speed control of a hybrid fuzzy neural network for a high performance IM drive to increase the performance and robustness of the IM drive under nonlinear loads and parameter variations.

In this paper, a novel speed controller for IMs has been presented. The control law is proposed based on feedback linearization technique. Two neurofuzzy systems have been designed to estimate the unknown nonlinear functions required in the control law. As mentioned before, many speed control approaches for induction motors have been presented in the literature without stability analysis. The contribution of this paper is presenting a rigorous mathematical stability analysis for neuro-fuzzy speed control of induction motors. The adaptation laws for training the parameters of neuro-fuzzy estimators are derived from the stability analysis in which the boundedness of fluxes and currents has been guaranteed. In order to guarantee the asymptotic convergence of the speed tracking error and improve the control system performance, the reconstruction errors of neuro-fuzzy systems have been compensated using a robustifying term in the control law. Recently, some algorithms have been proposed in the literature for the compensation of the reconstruction error. These algorithms result in discontinuous control laws due to the existence of the sign function, which may increase the possibility of the chattering phenomenon [28-33]. As an advantage over these approaches, this paper presents a continuous robustifying term. Moreover, simulation results show that the proposed controller represents acceptable robustness against variations of the external load disturbance. In addition the controller is capable of fast disturbance rejection due to the undesirable effects from the input voltage.

This paper is organized as follows; Section 2 describes the IM model. Section 3 presents the proposed control law and stability analysis. Simulation results are given in section 4 and finally, section 5 concludes the paper.

\section{Induction motor model}

The fifth-order model of an IM under the assumptions of equal mutual inductances and linear magnetic circuit is given by:

$$
\begin{aligned}
& \frac{d i_{s a}}{d t}=-a_{0} i_{s a}+a_{1} \psi_{r a}+a_{2} \omega \psi_{r b}+a_{3} u_{s a} \\
& \frac{d i_{s b}}{d t}=-a_{0} i_{s b}+a_{1} \psi_{r b}-a_{2} \omega \psi_{r a}+a_{3} u_{s b} \\
& \frac{d \psi_{r a}}{d t}=-\frac{R_{r}}{L_{r}} \psi_{r a}-n_{p} \omega \psi_{r b}+\frac{R_{r}}{L_{r}} M i_{s a} \\
& \frac{d \psi_{r b}}{d t}=-\frac{R_{r}}{L_{r}} \psi_{r b}+n_{p} \omega \psi_{r a}+\frac{R_{r}}{L_{r}} M i_{s b}
\end{aligned}
$$




$$
\frac{d \omega}{d t}=\frac{n_{p} M}{J L_{r}}\left(\psi_{r a} i_{s b}-\psi_{r b} i_{s a}\right)-\frac{T_{L}}{J}
$$

where, $u_{s}, i, T_{L}$, and $\psi$ indicate stator voltage input to the machine, current, external load torque, and flux linkage respectively; the subscripts $r$ and $s$ stand for rotor and stator; $(a, b)$ denote the components of a vector with respect to a fixed stator reference frame and, $\sigma=1-\left(M^{2} / L_{s} L_{r}\right)$, $a_{0}=\left(M^{2} R_{r}+L_{r}^{2} R_{s}\right) /\left(\sigma L_{s} L_{r}^{2}\right), \quad a_{3}=1 /\left(\sigma L_{s}\right)$ $a_{1}=\left(M R_{r}\right) /\left(\sigma L_{s} L_{r}^{2}\right), a_{2}=\left(n_{p} M\right) /\left(\sigma L_{s} L_{r}\right),[34-37]$.

\section{The proposed control scheme}

Consider the following general form of nonlinear systems

$\dot{x}_{n}=f_{1}(X)+g(X) u$

in which $f_{1}(X)$ and $g(X)$ are unknown nonlinear functions and $X$ is the state variable vector defined as $X=\left[\begin{array}{llll}x_{1} & x_{2} & \ldots & x_{n}\end{array}\right]^{T}$. According to (1), it is clear that $X=\left[\begin{array}{lllll}i_{s a} & i_{s b} & \psi_{r a} & \psi_{r b} & \omega\end{array}\right]^{T}$ is the state vector of this system. The time derivative of (1-e) is $\ddot{\omega}=h(X, t)+g(X, t) u$

in which $u$ is the input voltage amplitude of stator and $h(X, t)$ and $g(X, t)$ are

$$
\begin{gathered}
h(X, t)=b_{0}\left(i_{s a} \psi_{r a}+i_{s b} \psi_{r b}\right) \\
+b_{1}\left(i_{s a} \psi_{r b}-i_{s b} \psi_{r a}\right)+b_{2}\left|\psi_{r}\right|^{2} \\
g=c_{0} \frac{\sqrt{3}}{3} \psi_{r a}\left(\sin \left(\alpha \mathrm{t}-\frac{2 \pi}{3}\right)-\sin \left(\alpha \mathrm{t}+\frac{2 \pi}{3}\right)\right) \\
-c_{1}\left(2 \sin (\alpha \mathrm{t})-\sin \left(\alpha \mathrm{t}-\frac{2 \pi}{3}\right)-\sin \left(\alpha \mathrm{t}+\frac{2 \pi}{3}\right)\right)
\end{gathered}
$$

in which $\left|\psi_{r}\right|^{2}=\psi_{r b}^{2}+\psi_{r a}^{2}, b_{0}=-\left(n_{p}^{2} M \omega\right) /\left(J L_{r}\right)$, $\mathrm{b}_{1}=\frac{R_{r} n_{p} M}{J L_{r}^{2}}+a_{0} \frac{a_{2}}{J a_{3}}, \quad b_{2}=-n_{p}^{2} M^{2} \omega /\left(\sigma J L_{s} L_{r}^{2}\right)$, $c_{0}=\frac{n_{p} M}{\sigma J L_{s} L_{r}}$ and $c_{1}=\frac{n_{p} M \psi_{r b}}{3 \sigma J L_{s} L_{r}}$. Based on feedback linearization, consider the following control law:

$$
u=\frac{\ddot{\omega}_{d}+k_{d} \dot{e}+k_{p} e-h(X, t)}{g(X, t)}
$$

in which $e=\omega_{r}-\omega$ is the speed tracking error and $k_{p}, \quad k_{d}$ are design parameters. So for implementation of the control law, the acceleration signal $\dot{\omega}$ is required and because this feedback is contaminated with noise, the performance of control system is deteriorated. In order to reduce the system order and remove the acceleration feedback we can rewrite the (3) as follows

$$
\ddot{\omega}=h(X, t)+g(X, t) u+\dot{\omega}-\dot{\omega}
$$

which can be shown in form (2) as:

$\dot{\omega}=f(X, t)+g(X, t) u$

in which $f(X, t)=h(X, t)+\dot{\omega}-\ddot{\omega}$ and $g(X, t)$ are unknown nonlinear functions. Based on feedback linearization, consider the following proposed control law:

$$
u=\frac{-\hat{f}(X, t)+\dot{\omega}_{r}+k_{p} e+k_{I} \int e d t+u_{r}}{\hat{g}(X, t)}
$$

in which $\dot{\omega}_{r}$ is the derivative of reference speed $\omega_{r}$ , $e=\omega_{r}-\omega$ is the speed tracking error, $k_{p}, k_{d}$ are design parameters, $\hat{f}(X, t)$ and $\hat{g}(X, t)$ are the neuro-fuzzy estimations of $f(X, t)$ and $g(X, t)$, and $u_{r}$ is the robustifying control term to compensate the reconstruction errors of the neurofuzzy systems $\hat{f}$ and $\hat{g}$. The structure of the speed control system is illustrated in figure 1 in which $V_{\text {dist }}$ is the undesirable disturbance of the input voltage.

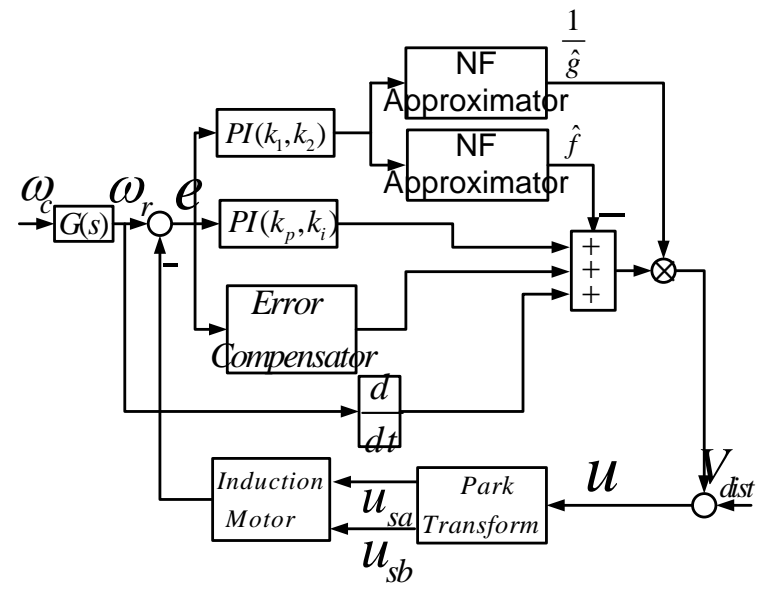

Figure 1. The structure of proposed control system.

In figure 2 the signal propagation in each layer of neuro-fuzzy estimators is illustrated. In this figure $S=\left[\begin{array}{llll}s_{1} & s_{2} & \cdots & s_{n}\end{array}\right]^{T}$ is the input variable vector and $\quad \mu_{i}^{j}\left(s_{i}\right)=\exp \left[-\left(s_{i}-m_{i}^{j}\right)^{2} /\left(\sigma_{i}^{j}\right)^{2}\right]$ is the Gaussian membership function, in which $m_{i}^{j}$ ( $i=1, \ldots n$ and $j=1, \ldots, N)$ is the mean of the Gaussian function in the $j^{\text {th }}$ term of the $i^{\text {th }}$ input variable $s_{i}$, and $\sigma_{i}^{j}$ is its corresponding standard deviation. In this paper each input variable has two linguistic fuzzy sets as negative and positive thus, $N$ is set to 2 . Also in the $k^{\text {th }}$ node in the rule layer $(k=1, \ldots, p)$, the fuzzy AND operation determines the output by multiplying the input signals as $\xi_{k}(S)=\prod_{i=1}^{n} w_{j i}^{k} \mu_{i}^{j}\left(s_{i}\right)$ where $w_{j i}^{k}$ is 
unity weights between the membership layer and the rule layer, and $p$ is the number of rules. $y_{o}=\sum_{k=1}^{p} \theta_{o k} \xi_{k}(S)$ is one of the overall outputs that is the summation of its inputs by considering related weights $\theta_{o k}$ way to comply with the journal paper formatting requirements is to use this document as a template and simply type your text into it.

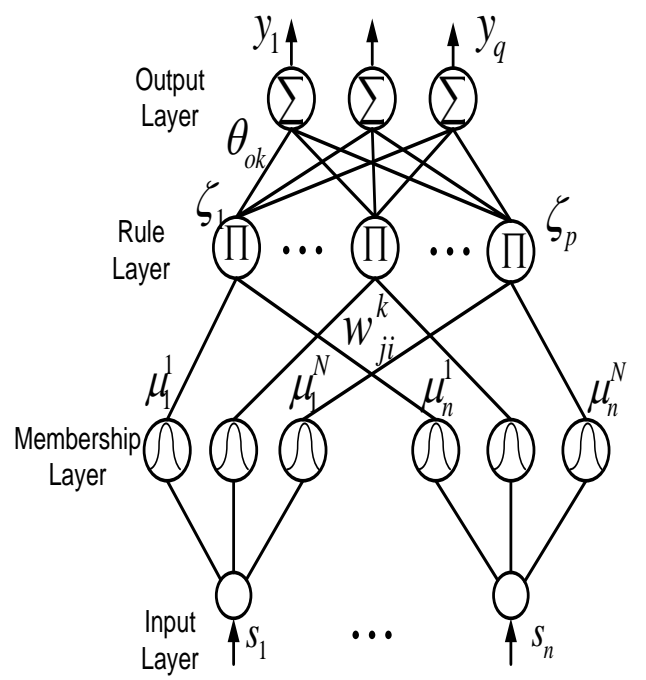

Figure 2. The structure of the neuro-fuzzy approximators.

In this paper, $\hat{f}(X, t)$ and $\hat{g}(X, t)$ are estimated using two neuro-fuzzy systems. The input of each system is given by the PI structure shown in figure 1 . This filter is very common in the speed control of electrical motors and often improves the tracking performance of the controllers. The input-output relation of this filter is described by $s(t)=k_{1} e(t)+k_{2} \int_{0}^{t} e(\tau) d \tau$ in which $k_{1}$ and $k_{2}$ are positive tuning parameters. In this paper, the input and output of neuro-fuzzy systems are scalars. Thus, we can write the output of neuro-fuzzy approximators as follows:

$y=\theta^{T} \xi$

where, $\theta=\left[\theta_{1}, \theta_{2}\right]^{T}$ is the consequent adjustable parameter vector and $\xi=\left[\xi_{1}, \xi_{2}\right]^{T}$. From (8), the closed loop equation is given by $\dot{\omega}_{r}-\dot{\omega}=\dot{\omega}_{r}-f(X, t)-g(X, t) u$

Substituting $u$ from (9) into (11) yields $\dot{e}+k_{p} e+k_{I} \int e=(\hat{f}-f)+(\hat{g}-g) u-u_{r}$

According to (10), it follows from (12) that

$$
\begin{aligned}
\dot{e}= & -k_{p} e-k_{I} \int e d t+\left(\hat{\theta}_{f}-\theta_{f}\right)^{T} \xi \\
& +\left(\hat{\theta}_{g}-\theta_{g}\right)^{T} \eta u-u_{r}
\end{aligned}
$$

By defining $E=\left[\int \begin{array}{ll}e d t & e\end{array}\right]^{T}$, we have:

$$
\dot{E}=A E+B\left\{(\hat{f}-f)+(\hat{g}-g) u-u_{r}\right\}
$$

in which $A=\left[\begin{array}{cc}0 & 1 \\ -k_{I} & -k_{p}\end{array}\right]$ and $B=\left[\begin{array}{l}0 \\ 1\end{array}\right]$. Suppose that $f^{*}=\theta_{f}^{* T} \xi \quad$ and $\quad g^{*}=\theta_{g}^{* T} \eta \quad$ are the best approximations of $f$ and $g$. Therefore,

$$
\dot{E}=A E+B\left\{\hat{f}-f^{*}+\left(\hat{g}-g^{*}\right) u+\varepsilon-u_{r}\right\}
$$

where, $\quad \varepsilon=\left[f^{*}-f\right]+\left[g^{*}-g\right] u \quad$ is the reconstruction error (approximation error). According to the universal approximation theorem, $\varepsilon$ is bounded as $|\varepsilon|<\rho$ and it is assumed that $\rho$ is a positive known constant. By defining $\tilde{\theta}_{f}=\hat{\theta}_{f}-\theta_{f}^{*}$ and $\tilde{\theta}_{g}=\hat{\theta}_{g}-\theta_{g}^{*}$ $\dot{E}=A E+B\left\{\tilde{\theta}_{f}{ }^{T} \xi+\tilde{\theta}_{g}{ }^{T} \eta u_{I}+\varepsilon-u_{r}\right\}$

Theorem 1. Considering the nonlinear system (8) and the control law (9), if the following conditions are met, the internal signals in the control system are bounded and the tracking error converges to zero asymptotically:

$\dot{\hat{\theta}}_{f}=-\gamma_{1} E^{T} P B \xi$

$\dot{\hat{\theta}}_{g}=-\gamma_{2} E^{T} P B \eta u$

Proof. Consider the following positive definite function

$$
L=\frac{1}{2} E^{T} P E+\frac{1}{2 \gamma_{1}} \tilde{\theta}_{f}^{T} \tilde{\theta}_{f}+\frac{1}{2 \gamma_{2}} \tilde{\theta}_{g}^{T} \tilde{\theta}_{g}
$$

The time derivative of (19) is:

$$
\begin{aligned}
\dot{L} & =\frac{1}{2}\left(E^{T} A^{T}+\left\{\xi^{T} \tilde{\theta}_{f}+u \eta^{T} \tilde{\theta}_{g}+\varepsilon-u_{r}\right\}\right) P E \\
+ & \frac{1}{2}\left(E^{T} P\left(A E+b\left(\tilde{\theta}_{f}^{T} \xi+\tilde{\theta}_{g}^{T} \eta u+\varepsilon-u_{r}\right)\right)\right) \\
& +\frac{\tilde{\theta}_{f}^{T} \dot{\hat{\theta}}_{f}}{\gamma_{1}}+\frac{\tilde{\theta}_{g}^{T} \dot{\hat{\theta}}_{g}}{\gamma_{2}}
\end{aligned}
$$

According to the Lyapanove equation $A^{T} P+P A=-Q$. Since the matrix $A$ is a Hurwitz matrix, we can use this equation and simplify (20) as

$$
\begin{aligned}
\dot{L}= & E^{T} P B\left(\tilde{\theta}_{f}^{T} \xi+\tilde{\theta}_{g}^{T} \eta u+\varepsilon-u_{r}\right) \\
& +\frac{\tilde{\theta}_{f}^{T} \dot{\hat{\theta}}_{f}}{\gamma_{1}}+\frac{\tilde{\theta}_{g}^{T} \dot{\hat{\theta}}_{g}}{\gamma_{2}}-\frac{1}{2} E^{T} Q E
\end{aligned}
$$

In other words

$$
\begin{aligned}
\dot{L} & =\frac{-1}{2} E^{T} Q E+\left(E^{T} P B \tilde{\theta}_{f}^{T} \xi+\frac{\tilde{\theta}_{f}^{T} \dot{\hat{\theta}}_{f}}{\gamma_{1}}\right) \\
& +\left(E^{T} P B \tilde{\theta}_{g}^{T} \eta u+\frac{\tilde{\theta}_{g}^{T} \dot{\hat{\theta}}_{g}}{\gamma_{2}}\right)+E^{T} P B \varepsilon \\
& -E^{T} P B u_{r}
\end{aligned}
$$


Using (17) and (18), (22) can be simplified as

$\dot{L}=\frac{-1}{2} E^{T} Q E+E^{T} P B \varepsilon-E^{T} P B u_{r}$

Since $|\varepsilon|<\rho$ it follows from (23) that

$\dot{L} \leq \frac{-1}{2} E^{T} Q E+\left|E^{T} P B\right| \rho-E^{T} P B u_{r}$

Define $z=E^{T} P B$ thus

$\dot{L} \leq \frac{-1}{2} E^{T} Q E+|z| \rho-z u_{r}$

According to [18] we can propose the robustifying term as

$u_{r}=\frac{z \rho}{|z|+\lambda e^{-\beta t}}$

in which $\lambda$ and $\beta$ are constant positive scalars, so

$\dot{L} \leq \frac{-1}{2} E^{T} Q E+|z| \rho-\frac{z^{2} \rho}{|z|+\lambda e^{-\beta t}}$

After some manipulations, we can write

$\dot{L} \leq \frac{-1}{2} x^{T} Q x+\rho \frac{|z| \lambda e^{-\beta t}}{|z|+\lambda e^{-\beta t}}$

Since $\forall a>b>0: \frac{a b}{a+b}<b<a \quad$ we have

$\frac{|z| \lambda e^{-\beta t}}{|z|+\lambda e^{-\beta t}} \leq \lambda e^{-\beta t}$, therefore

$\dot{L} \leq \frac{-1}{2} E^{T} Q E+\rho \lambda e^{-\beta t}$

According to [18], (29) indicates that speed tracking error asymptotically converges to zero. To ensure the boundedness of internal dynamics of IM including $i_{r a}, i_{r b}, \psi_{s a}$ and $\psi_{s b}$, according to

(1) we can write

$\dot{X}_{1}=A X_{1}+v(t)$

in which

$X_{1}=\left[i_{s a} i_{s b} \psi_{r a} \psi_{r b}\right]^{T}$

$v(t)=\left[\begin{array}{cccc}\frac{1}{\sigma L_{s}} u_{s a} & \frac{1}{\sigma L_{s}} u_{s b} & 0 & 0\end{array}\right]^{T}$

and $A$ is given in (33). Since the eigenvalues of $A$ are negative, the state vector $X_{1}$ in $\dot{X}_{1}=A X_{1}$ is exponentially stable. Moreover, the control law (9) is bounded. Thus, the vector $v(t)$ is bounded. Consequently, the system (30) can be considered as a stable linear system with bounded inputs.

$$
A=\left[\begin{array}{cccc}
-a_{0} & 0 & \frac{M R_{r}}{\sigma L_{s} L_{r}^{2}} & \frac{n_{p} M}{\sigma L_{s} L_{r}} \omega \\
0 & -a_{0} & -\frac{n_{p} M}{\sigma L_{s} L_{r}} \omega & \frac{M R_{r}}{\sigma L_{s} L_{r}^{2}} \\
\frac{R_{r} M}{L_{r}} & 0 & -\frac{R_{r}}{L_{r}} & -n_{p} \omega \\
0 & \frac{R_{r} M}{L_{r}} & n_{p} \omega & -\frac{R_{r}}{L_{r}}
\end{array}\right]
$$

\section{Simulation results}

To make the superiority of the proposed method more obvious, its performance is compared with the controller designed in [23]. In Simulation 1 the proposed neuro-fuzzy control algorithm has been tested and Simulation 2 presents the performance of the adaptive fuzzy MIMO controller [23].

\subsection{Simulation 1}

Consider a three-phase standard IM with parameters given in the table 1 .

Table 1. Rated parameters of case study induction motor.

\begin{tabular}{lll}
\hline & & $3(\mathrm{KW})$ \\
$f$ & Power & $60(\mathrm{~Hz})$ \\
$V$ & Frequency & $380(\mathrm{~V})$ \\
$I$ & Rated voltage & $6.9(\mathrm{~A})$ \\
$n_{p}$ & Rated current & 2 \\
$R_{s}$ & Number of pole pairs & $1.115(\Omega)$ \\
$R_{r}$ & Stator resistance & $1.083(\Omega)$ \\
$L_{s}$ & Stotor resistance & $0.005974(\mathrm{H})$ \\
$L_{r}$ & Rotor inductance & $0.005974(\mathrm{H})$ \\
$M$ & Mutual inductance & $0.2037(\mathrm{H})$ \\
$J$ & Total inertia & $0.02(\mathrm{kgm} 2)$ \\
\hline
\end{tabular}

To test the control system robustness against the thermal variation of motor parameters and external load disturbance, it is assumed that

$$
\begin{array}{ll}
R_{s}=R_{s 0}(1+0.2 \sin (t)) & \Omega \\
R_{r}=R_{r 0}(1+0.2 \cos (t)) & \Omega \\
L_{s}=L_{s 0}(1+0.1 \sin (t)) & H \\
L_{r}=L_{r 0}(1+0.1 \cos (t)) & H
\end{array}
$$

and

$T_{L}= \begin{cases}2 N . M & t<12 \\ 8 N . M & 12 \leq t \leq 17 \\ 3 N . M & t>17\end{cases}$

In this paper, in order to examine the speed regulation capability in response to sudden variations of the speed command, $\omega_{c}$ has been defined the summation of the constant value 155 and a square wave (altitude $=10$, frequency $=0.1$ $\mathrm{Hz}$ ). Also by using a proper reference model the transient response of the speed control system has been regulated. Finally, in order to verify the ability of the proposed control law in rejecting input voltage disturbances, the following voltage disturbance has been inserted to $u$. 
$v_{\text {dist }}= \begin{cases}15 V & 8 \leq t \leq 9 \\ 0 V & \text { otherwise }\end{cases}$

The initial values of $\theta_{f}$ and $\theta_{g}$ in neuro-fuzzy systems have been set to 1 . Moreover, the learning rates of adaptation laws (13), (14), the proportional gain $K_{p}$ and $K_{I}$ in (5) have been selected as $\gamma_{1}=1000, \gamma_{2}=0.1, K_{p}=20 \quad$ and $K_{I}=100$. Also $\lambda$ and $\beta$ in (22) have been set to 1 and 0.1 respectively. The upper bound of the reconstruction error has been assumed as $\rho=1$.

The tracking performance of the proposed control scheme and the speed tracking error are illustrated in figure 3 , figure 4 and figure 5.

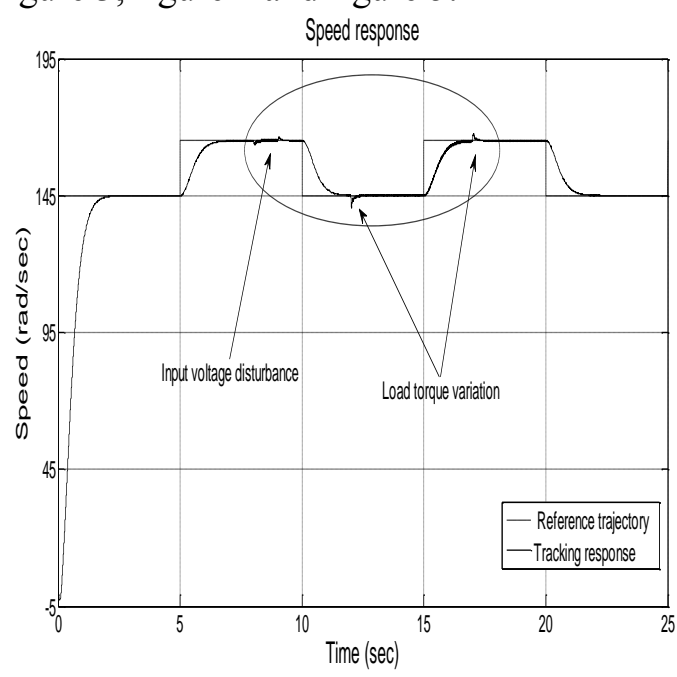

Figure 3.The tracking performance of the proposed control scheme.

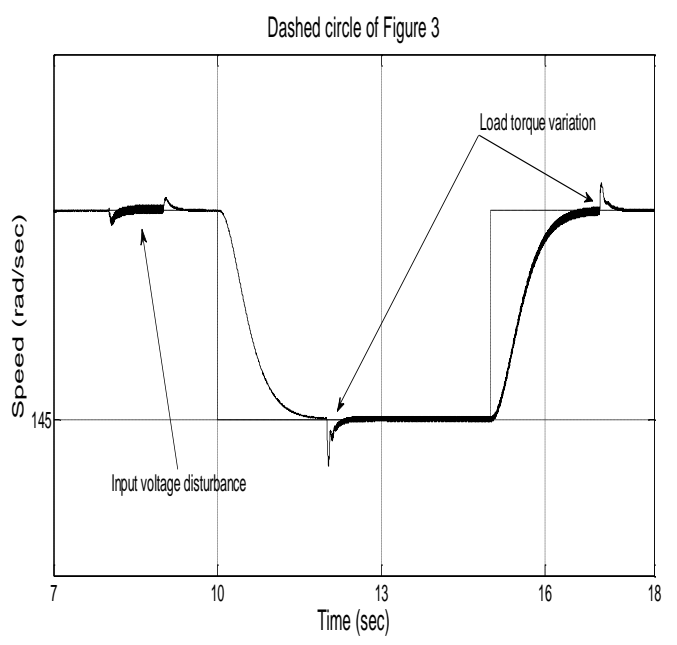

Figure 4. Dashed circle of the Figure 3 is zoomed.

As shown in these figures, the asymptotic convergence of the motor speed to the command signal is satisfying in terms of fast external load disturbance rejection and robustness against motor parameter variation and undesirable disturbances of the input voltage. Finally the control effort is presented in figure 6 .

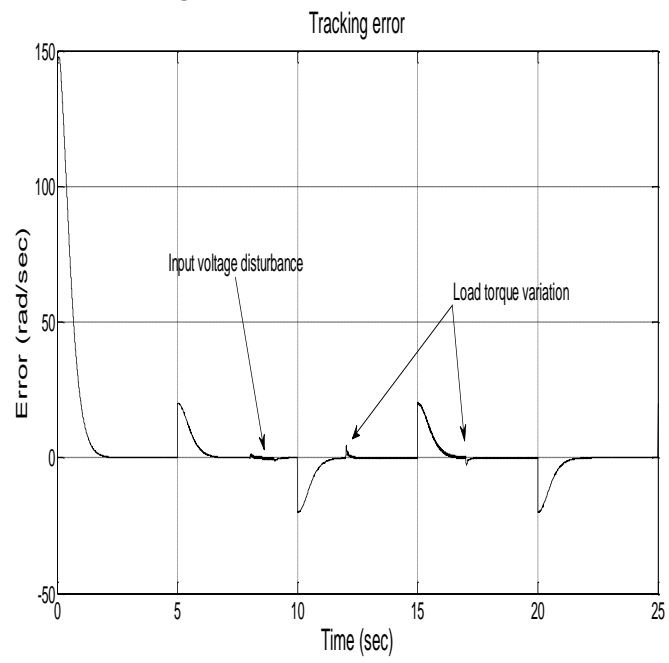

Figure 5.asymptotic convergence of tracking error.

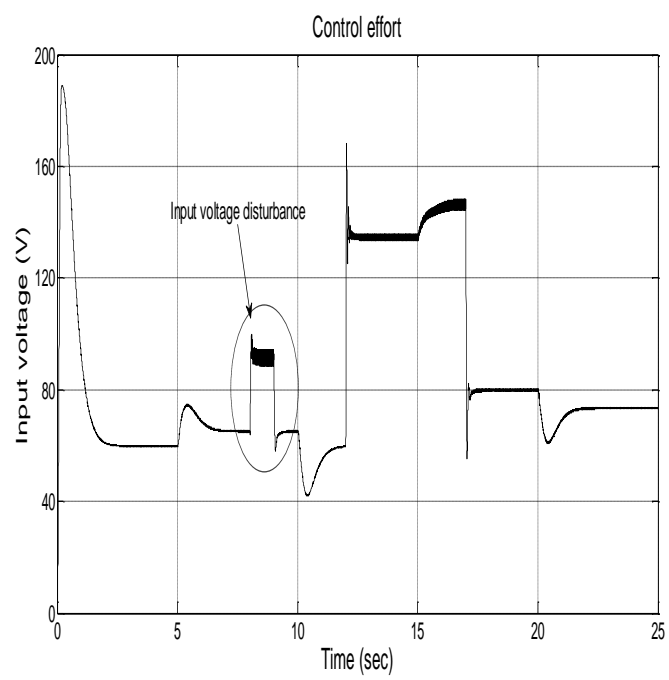

Figure 6. The control effort.
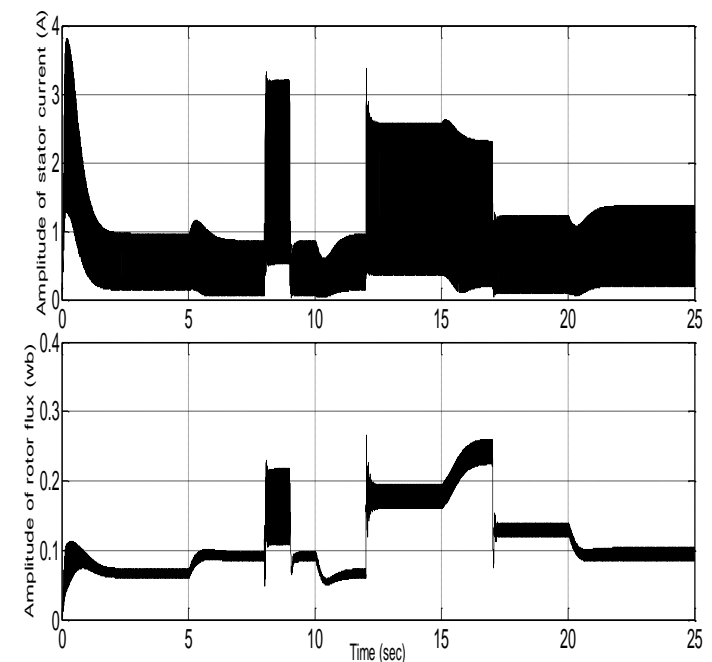

Figure 7. The value of modules for stator current and flux in the control system.

Moreover, as illustrated in this figure, the motor voltage is under the maximum permitted voltage. 
In addition, based on table 1 the amplitude of stator current $\sqrt{i_{s a}{ }^{2}+i_{s b}{ }^{2}}$ must be less than 6.9 A. Also the flux upper limit can be computed by multiplying flux density to pole cross section that achieved 0.48 so in this machine the $\sqrt{\psi_{r a}{ }^{2}+\psi_{r b}{ }^{2}}$ value must be less than or equal 0.48 . In the meantime, figure 7 shows bounded closed-loop signals for the proposed control system.

\subsection{Simulation 2}

In this simulation, the adaptive fuzzy MIMO control presented in [23] is used for the speed control of the IM model described in Simulation 1. The reference model, external load torque, and input voltage disturbances are the same as Simulation 1. The tracking performance of this control scheme is illustrated in figure 8 and figure 9. As shown in figure 9, this control approach fails in rejecting the external load torque and input voltage disturbances. However, as shown in figure 4 , the proposed method completely eliminates the effect of these disturbances. It should be noted that the adaptive fuzzy MIMO method [23], requires feedbacks from all state variables and also the acceleration signal is used, while the proposed controller needs just the speed feedback. Moreover, there are six uncertain functions which should be estimated in the adaptive fuzzy MIMO method. In order to estimate each function, 243 fuzzy rules are needed. However, the neuro-fuzzy approach presented in this paper is much simpler and less computational. In addition, the nonsingularity of the estimated input gain matrix in [23] is a critical condition which can be violated easily and make the control system unstable.

Another superiority of the proposed controller is compensating the reconstruction error of the neuro-fuzzy estimator which has improved the performance of the controller. The cost function $J=\int_{0}^{30} e^{2}(t) d t$ has been defined for quantitative comparisons. In the proposed method $J=3.137$ while the method presented in [23] results in $J=6.457$.

\section{Conclusion}

Speed control of induction motors is very important in many industrial applications such as pump actuators, milling machines and elevators. In this paper an indirect adaptive system for the speed control of IMs is presented in which the uncertainty including parametric variations, the external load disturbance and unmodeled dynamics is estimated and compensated by designing two neuro-fuzzy systems with online training approaches based on Lyapunov stability analysis. In order to guarantee the asymptotic convergence of the speed tracking error and improve the control system performance, the reconstruction errors of neuro-fuzzy systems is compensated using a robustifying term in the control law. Finally, high performance characteristics and robustness of the proposed control system against plant parameter variation, external load and input voltage disturbances are verified by the simulation results.

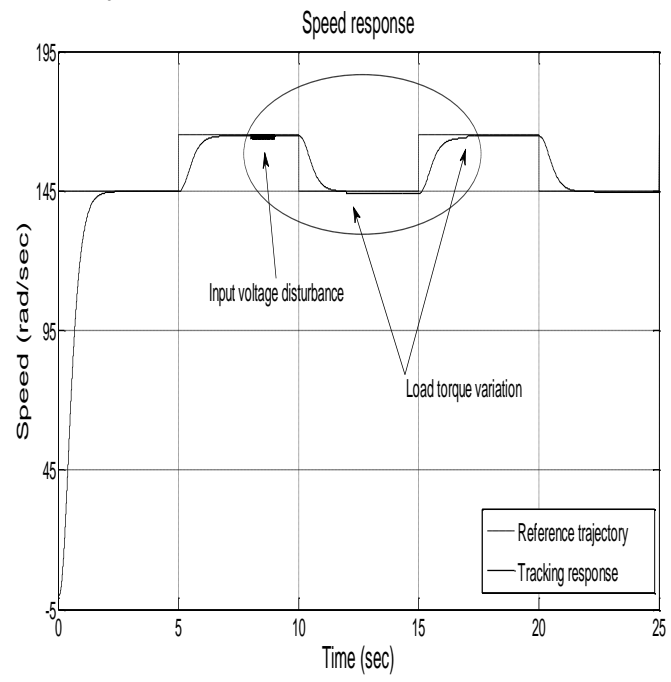

Figure 8. The tracking performance of the adaptive fuzzy MIMO method [23].

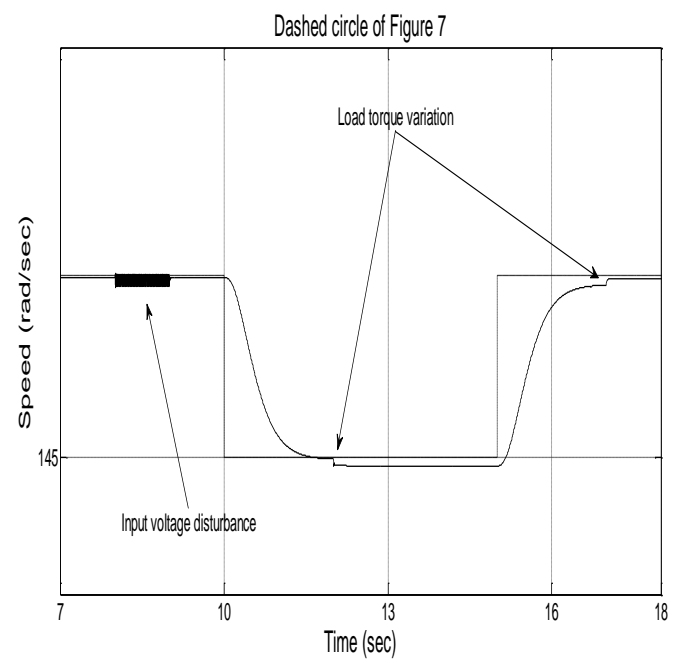

Figure 9. Dashed circle of the Figure 8 is zoomed.

\section{References}

[1] Kim, G. S., Ha, I. J. \& Ko, M. S. (1992). Control of induction motors for both high dynamic performance and high power efficiency. IEEE Tran Ind Electron, vol. 39, pp. 323-333.

[2] Bodson, M., Chiasson, J. \& Novotnak, R. (1994). High-performance induction motor control via inputoutput linearization. IEEE Contr Syst Mag, vol. 14, pp. 25-33. 
[3] Liaw, C. M., Kung, Y. S. \& Wu, C. M. (1991). Design and implementation of a high-performance field-oriented induction motor drive. IEEE Trans Ind Electron, vol. 38, pp. 275-282.

[4] Takahashi, I. \& Noguchi, T. (1986). A new quickresponse and high-efficiency strategy of an induction motor. IEEE Trans Ind Appl, vol. 1, pp. 820-827.

[5] Nash, JN. (1997). Direct torque control, induction motor vector control without an encoder. IEEE Trans Ind Appl, vol. 33, pp. 333-341.

[6] Buja, G. (1998). A new control strategy of the induction motor drives: The direct flux and torque control. IEEE Ind Electron Newslett, vol. 45, pp. 1416.

[7] Wang, W. J. \& Chen, J. Y. (2005). Passivity-based sliding mode position control for induction motor drives. IEEE Trans Energy Convers, vol. 20, pp. 316321.

[8] Shiau, L. G \& Lin, J. L. (2001). Stability of slidingmode current control for high performance induction motor position drives. In: IEE Proceedings of Electric Power Applications, pp. 69 -75.

[9] Barambones, O. \& Alkorta, P. (2011). An Adaptive Sliding Mode Position Control for Induction Motor Drives. In: International Conference on Computer as a Tool, EUROCON, Lisbon, Portugal, pp. 1-4.

[10] Barambonesa O., Alkortab, P., \& Gonzalez de Durana, J. M. (2014). A real-time estimation and control scheme for induction motors based on sliding mode theory. Journal of the Franklin Institute, vol. 351, pp. 4251-4270.

[11] Alonge, F. \& Raimondi, T. (1995). Indirect adaptive speed control of induction motor systems based on model reference identifiers. In: Proceedings of the 1995 IEEE IECON 21st International Conference on, pp. 1035-1040.

[12] Lin, Y. C., Fu, L. C. \& Tsai, C. Y. (1999). Nonlinear sensorless indirect adaptive speed control of induction motor with unknown rotor resistance and load. In: American Control Conference, San Diego, CA: USA, pp. 2168-2172.

[13] Halbaoui, K., Boukhetala, D. \& Boudjema, F. (2008). New robust model reference adaptive control for induction motor drives using a hybrid controller. In: Power Electronics, Electrical Drives, Automation and Motion, SPEEDAM 2008, Ischia, Italy, pp. 1109-1113.

[14] Behzad, H., Khorashadizadeh, S., \& Kalat, A. A. (2011). A robust adaptive method to control the crushing mill machine. In Control, Instrumentation and Automation (ICCIA), 2011 2nd International Conference on (pp. 547-551). IEEE.

[15] Fateh, M. M., \& Khorashadizadeh, S. (2012). Optimal robust voltage control of electrically driven robot manipulators. Nonlinear Dynamics, vol. 70, no. 2, pp. 1445-1458.
[16] Li, j. \& Zhong, Y. (2012). Robust speed control of induction motor drives employing first-order autodisturbance rejection controllers. In: Industry Applications Society Annual Meeting, IAS, Las Vegas, NV: USA, 1-7.

[17] Astrom, K. J. \& Wittenmark, B. (1994). Adaptive Control. 2nd ed. Prentice Hall.

[18] Khorashadizadeh, S., \& Fateh, M. M. (2014). Robust task-space control of robot manipulators using Legendre polynomials for uncertainty estimation. Nonlinear Dynamics, vol. 79, no. 2, pp. 1151-1161.

[19] Fateh, M. M., Ahmadi, S. M. \& Khorashadizadeh, S. (2014). Adaptive RBF Network Control for Robot Manipulators. Journal of AI and Data Mining, vol. 2, no. 2, pp. 159-166.

[20] Fateh, M. M. \& Azargoshasb, S., \& Khorashadizadeh, S. (2014). Model-free discrete control for uncertain robot manipulators using a fuzzy estimator. COMPEL: The International Journal for Computation and Mathematics in Electrical and Electronic Engineering, vol. 33, no. 3, pp. 1051-1067.

[21] Slotine, J. J. \& Li, W. (1991). Applied nonlinear control. Prentice Hall.

[22] Agamy, M. S., Yousef, H. A. \& Sebakhy, O.A. (2004). Adaptive fuzzy variable structure control of induction motors. In: Electrical and Computer Engineering. Canadian Conference on, Niagara Falls: Canada, pp. 89-94.

[23] Yousef, H. A. \& Wahba, M. A. (2009). Adaptive fuzzy mimo control of induction motors. Expert Syst Appl. vol. 36, pp. 4171-4175.

[24] Fateh, M. M., \& Khorashadizadeh, S. (2012). Robust control of electrically driven robots by adaptive fuzzy estimation of uncertainty. Nonlinear Dynamics, vol. 69, no. 3, pp. 1465-1477.

[25] Kusagur, A., Kodad, S. F. \& Sankar, Ram, B. V. (2012). Modelling \& Simulation of an ANFIS controller for an AC drive. World J of Model Simul, vol. 8 , pp. 36-49.

[26] Zerikat, M. \& Hekroun, S. (2008). High performance speed tracking of IM using an adaptive fuzzy NN control. Int J Sci Tech Autom Control Comp Eng IJ-STA Special Issue, pp. 516-531.

[27] Wang, L. X. (1994). Adaptive fuzzy systems and control: Design and stability analysis. Englewood Cliffs, NJ: Prentice Hall Inc.

[28] Shahnazi, R., ModirShanechi, H. \& Pariz, N. (2008). Position Control of Induction and DC Servomotors: A Novel Adaptive Fuzzy PI Sliding Mode Control. IEEE Trans Energy Convers, vol. 23, pp. 138-147.

[29] Lin, C. M. \& Hsu, C. F. (2004). Adaptive fuzzy sliding mod control of inductions servomotor systems. IEEE Trans Energy Convers, vol. 19, pp. 362-368. 
[30] Khorashadizadeh, S., \& Fateh, M. M. (2013). Adaptive fourier series-based control of electrically driven robot manipulators. In Control, Instrumentation, and Automation (ICCIA), 2013 3rd International Conference on (pp. 213-218). IEEE.

[31] Fard, M. B., \& Khorashadizadeh, S., (2015), Model free robust impedance control of robot manipulators using fourier series expansion. In AI \& Robotics (IRANOPEN), (pp. 1-7). IEEE

[32] Khorashadizadeh, S., \& Fateh, M. M., (2015), uncertainty estimation in robust tracking control of robot manipulators using the Fourier series expansion, Robotica, In press.

[33] Khorashadizadeh, S., Fateh, M. M., \& Azargoshasb S., (2014), Compensating the reconstruction error of fuzzy estimator in robust modelfree control of electrically driven robot manipulators, 14th Iranian Conference on Fuzzy Systems, pp. 99104.
[34] Fitzgerald, AE. \& Kingsley, C. J. (2002). Electric Machinery. 6th ed. New York, NY, USA: McGrawHill.

[35] Krause, P. C. \& Wasynczuk, O. (2002). Analysis of Electric Machinery and Drive Systems. 2nd edition. New York, NY, USA, McGraw-Hill.

[36] Leonhard, W. (2001). Control of Electrical Drives. 3rd ed. Berlin, Germany: Springer

[37] Krause, P. C. \& Thomas, C. H. (1965). Simulation of symmetrical induction machinery. IEEE Trans Power Ap Syst, vol. 84, pp. 1038-1053. 
كنترل سرعت موتور القايیى به روش عصبى -فازى تطبيقى غير مستقيم

مجتبى واحدى"، محمد حداد ظريف و على اكبرزاده كلات

دانشكده برق، دانشكاه صنعتى شاهرود، شاهرود، ايران.

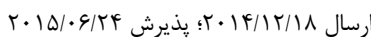

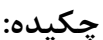

اين مقاله، يك سيستم تطبيقى غير مستقيم مبتنى بر تخمين گرهاى عصبى-فازى براى كنترل سرعت موتورهاى القـايى ارائسه مسىهــد. عـدم قطعيـت

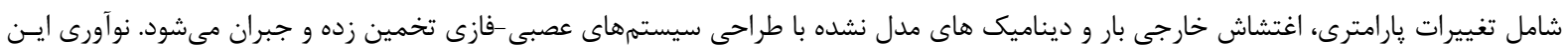

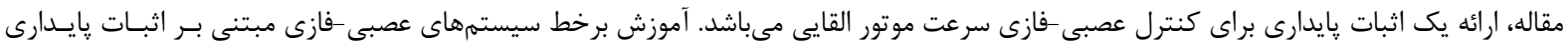

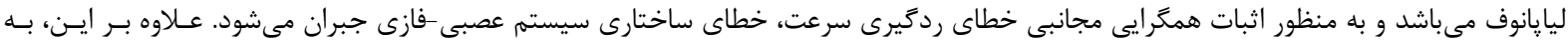

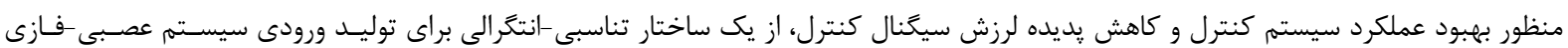

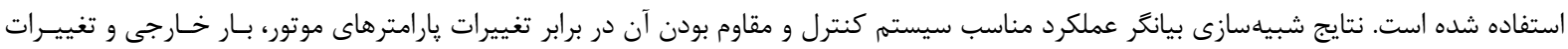
ولتاز ورودى موتور مىباشد.

كلمات كليدى: موتور القيى، كنترل تطبيقى غير مستقيم، تخمينكر عصبى -فازى، تخمين عدم قطعيت، اثبـات بايــارى، خطـاى سـاختارى سيسـتم عصبى-فازى. 